\title{
ESTUDO DA VARIAÇÃO DA CONCENTRAÇÃO DE METANO NO BIOGÁS PRODUZIDO A PARTIR DAS ÁGUAS RESIDUÁRIAS DO CAFÉ
}

\author{
A study on the variation of methane concentration in \\ biogas produced from coffee wastewater
}

\author{
Marco Antônio Calil Prado 1 , Cláudio Milton Montenegro Campos², Julia Ferreira da Silva ${ }^{3}$
}

\begin{abstract}
RESUMO
A água residuária do café (ARC), originada no processamento dos frutos do cafeeiro, produz quantidade considerável de biogás que pode e deve ser utilizado como fonte de energia alternativa e complementar. Neste trabalho, foi estudada a variação da concentração de metano do biogás produzido a partir das ARC, por tratamento anaeróbio, em reator UASB, em escala laboratorial. As amostras foram coletadas durante 86 dias. As análises da concentração de metano foram realizadas por cromatografia gás-sólido (CGS). A produção de biogás e de metano, foi de 0,545 a $0,602 \mathrm{~m}^{3} \mathrm{~kg}^{-1} \mathrm{DQO}$ removida e de 0,382 a $0,421 \mathrm{~m}^{3} \mathrm{~kg}^{-1}$ DQO removida, respectivamente. Os resultados da concentração de metano no biogás variaram de 48,60 a 68,14 $\%$, influenciados pela variação dos parâmetros temperatura, $\mathrm{pH}$, acidez e compostos fenólicos presentes nas ARC. Como havia sido previsto, as maiores concentrações de metano foram verificadas nos períodos em que o pH estava mais próximo da neutralidade.
\end{abstract}

Termos para indexação: Tratamento anaeróbio, reator UASB, cromatografia gasosa, metano.

\section{ABSTRACT}

The wastewater produced from wet coffee processing (WCP), originated from the coffee fruits, can produce great quantities of biogas, which, in turn, can be also used as an alternative or complementary energy source. In this research, we studied the variation of methane concentration produced by WCP in a laboratory-scale UASB reactor with anaerobic treatment. The samples were collected during a period of 86 days. The methane concentration was measured through gas solid chromatography (GSC). The production of biogas and methane ranged from 0.545 to $0.602 \mathrm{~m}^{3} \mathrm{~kg}^{-1} \mathrm{DQO}$ removed and from 0.382 a $0.421 \mathrm{~m}^{3} \mathrm{~kg}^{-1}$ DQO removed, respectively. Methane presence in the biogas ranged from $48.60 \%$ to $68.14 \%$. This variation was influenced by the following parameters: temperature, $\mathrm{pH}$, acidity, and phenol compounds present in the WCP. As expected, greater concentrations of methane gas were verified during the periods when the $\mathrm{pH}$ close to neutral.

Index terms: Anaerobic treatment, UASB reactor, gas chromatography, methane.

(Recebido em 9 de novembro de 2006 e aprovado em 18 de setembro de 2009)

\section{INTRODUÇÃO}

A dependência energética do setor agrícola com relação aos combustíveis fósseis é uma questão que merece ser discutida. O consumo de combustíveis desta origem representa aproximadamente $60,5 \%$ da energia consumida no setor agrícola. Então, há que se considerar, o desperdício da energia, quando não se aproveitam os resíduos agroindustriais e, também, a poluição ambiental causada pela disposição não controlada destes no ambiente (Prado, 2006).

Um importante aspecto da bioenergia é seu potencial em contribuir na solução de problemas ambientais causados pelo uso de combustíveis fósseis (Lora \& Andrade, 2009).

O biogás, conhecido como o gás dos pântanos, foi descoberto por Shirley em 1667 e é produzido por fenômenos naturais existentes em várias partes do planeta, como em pântanos, oceanos e água doce e por fontes antropogênicas, como em plantações de arroz alagado, tratamento de efluentes, aterro sanitário, etc. (Cassini, 2003). De acordo com Metcalf \& Eddy (2003), o biogás é composto, na sua maior parte, de metano $\left(\mathrm{CH}_{4}\right)$ e dióxido de carbono $\left(\mathrm{CO}_{2}\right)$, contendo, ainda, traços de vapor de água ( $\left.\mathrm{H}_{2} \mathrm{Ovapor}\right)$, gás sulfídrico $\left(\mathrm{H}_{2} \mathrm{~S}\right)$, nitrogênio $\left(\mathrm{N}_{2}\right)$, oxigênio $\left(\mathrm{O}_{2}\right)$, hidrogênio $\left(\mathrm{H}_{2}\right)$, monóxido de carbono ( $\mathrm{CO})$, amônia $\left(\mathrm{NH}_{3}\right)$, mercaptanas e outros gases.

A digestão anaeróbia, ou fermentação metanogênica, é produzida por grupos de bactérias fermentativas hidrolíticas, bactérias fermentativas acidogênicas, bactérias acetogênicas e pelas Archaeas metanogênicas, as quais são as responsáveis pela

\footnotetext{
${ }^{1}$ Centro Federal de Educação Tecnológica de Minas Gerais - Campus Nepomuceno - Nepomuceno, MG

2Universidade Federal de Lavras/UFLA - Departamento de Engenharia/DEG - Cx. P. 3037 - 37200-000 - Lavras, MG - cmmcampos@ufla.br

${ }^{3}$ Universidade Federal de Lavras/UFLA - Departamento de Biologia/DBI - Lavras, MG
} 
produção de metano (Barreto \& Campos, 2009). De acordo com Luste et al. (2009), esse processo oferece diversas vantagens, como a minimização da quantidade de efluentes orgânicos lançados no ambiente e da emissão de gases e seus materiais oriundos da degradação incontrolada e, ainda, a produção de biogás, com teor de metano de 50 a 70\%, que pode ser usado como eletricidade, fonte de calor e, também, combustível veicular.

Uma vez que, os compostos orgânicos, presentes nas águas residuárias oriundas das etapas de descascamento, desmucilamento e lavagem, são ricos em carboidratos e possuem também considerável valor energético, as ARC podem ser tratadas por processos de digestão anaeróbia, o que possibilita a diminuição do seu potencial poluidor e garante a produção de subprodutos, como o lodo, o efluente líquido clarificado e o biogás (Campos et al., 2002), que pode e deve ser utilizado como fonte de energia alternativa e complementar, podendo ser usado, inclusive, no seu processo de secagem, já que é de grande necessidade a busca da redução dos gastos energéticos e da utilização de novas fontes substitutas ou complementares na secagem do café (Prado, 2006).

Uma boa opção para o tratamento das ARC são os reatores anaeróbios UASB (UpFlow Anaerobic Sludge Blanket Reactors), que possuem boa eficiência de conversão da matéria orgânica em subprodutos estabilizados por bactérias anaeróbias (Sperling, 1996b). Segundo Campos (1990), Sperling (1996a) e Metcalf \& Eddy (2003), o UASB é um tipo de reator anaeróbio de fluxo ascendente (RAFA), que possui mecanismos de retenção de sólidos, baixo tempo de detenção hidráulica (TDH), é capaz de suportar altas cargas volumétricas, além de ser compacto e apresentar boa eficiência na remoção da carga poluidora dos efluentes. A matéria orgânica é estabilizada anaerobiamente pelas bactérias dispersas no reator, não necessitando de um meio suporte. A parte superior do reator é dividida nas zonas de sedimentação, que permitem a saída do efluente clarificado e o retorno dos sólidos (biomassa) e no sistema de coleta de gás.

Campos (1990), Metcalf \& Eddy (2003) e Chernicharo (2007) citam que a composição global do biogás produzido, bem como a sua concentração de metano, varia de acordo com uma série de fatores, tais como a composição química do efluente a ser tratado, a temperatura, o $\mathrm{pH}$, a acidez e a alcalinidade do meio e, ainda, os nutrientes a serem usados pelas populações microbianas.

Outros fatores que interferem na produção de biogás são: o tipo de reator, a atividade metanogênica da biomassa, o tempo de residência celular, a presença de substâncias inibidoras e ou limitantes do próprio processo, como o excesso de ácidos graxos voláteis e produtos alcalinos, a presença de substâncias tóxicas às bactérias e as variações nos parâmetros quantitativos operacionais do reator, tais como a vazão, a carga, o tempo de detenção hidráulica (TDH) e a velocidade do fluxo (Chernicharo, 2007).

Nesta pesquisa objetivou-se estudar a variação da concentração de metano no biogás, produzido a partir das águas residuárias do café coco, da espécie Coffea arabica L., tratadas anaerobiamente em reator UASB, inserido em um sistema de tratamento em escala laboratorial.

\section{MATERIAL E MÉTODOS}

\section{Sistema de tratamento}

O experimento, em escala laboratorial, foi realizado no Laboratório de Análise de Água, do Departamento de Engenharia (LAADEG), da Universidade Federal de Lavras (UFLA), assim como as análises laboratoriais. Para a análise da concentração de metano no biogás, utilizouse cromatografia gasosa gás-sólido (CGS), com análises realizadas na Central de Análises e Prospecção Química (CAPQ), do Departamento de Química (DQI), da UFLA.

Para o tratamento das ARC e para quantificar a produção do biogás, foi utilizado um sistema, em escala laboratorial, composto por um tanque de acidificação e equalização (TAE), que era um container de polietileno, cilíndrico, de altura $0,63 \mathrm{~m}$, raio de $0,16 \mathrm{~m}$ e volume útil de 45 litros. Na saída do TAE, foi instalada a bomba de deslocamento positivo, marca Prominent, modelo Gala 1602 Gamma/L M70, de pressão máxima 10 bar e vazão máxima de 2,1 $\mathrm{L} \mathrm{h}^{-1}$, utilizada para bombear o efluente do TAE para o UASB. O UASB, o gasômetro, o equalizador de pressão e a lagoa aerada facultativa (LAF) foram construídos de vidro com $3 \mathrm{~mm}$ de espessura. O UASB possuía largura e profundidade de $0,161 \mathrm{~m}$, altura de $0,603 \mathrm{~m}$ e volume útil de 12,54 L. O gasômetro possuía volume útil de 16,87 L e o equalizador de pressão de 2,61 L. Do UASB o efluente seguia para a LAF, que possuía largura de 0,490 m, profundidade de $0,192 \mathrm{~m}$, altura de $0,202 \mathrm{~m}$ e volume útil de 13,0 L. No sistema de aquecimento, nas tubulações e no UASB, utilizou-se um revestimento de isopor como isolante térmico, para evitar trocas de calor com o meio (Figura 1).

Os pontos de coleta das amostras eram o afluente do reator UASB (A-UASB) e o efluente do reator UASB (E-UASB). A amostragem de biogás para análise foi realizada em um período de 86 dias, de 06/04/06 a 30/06/06. 


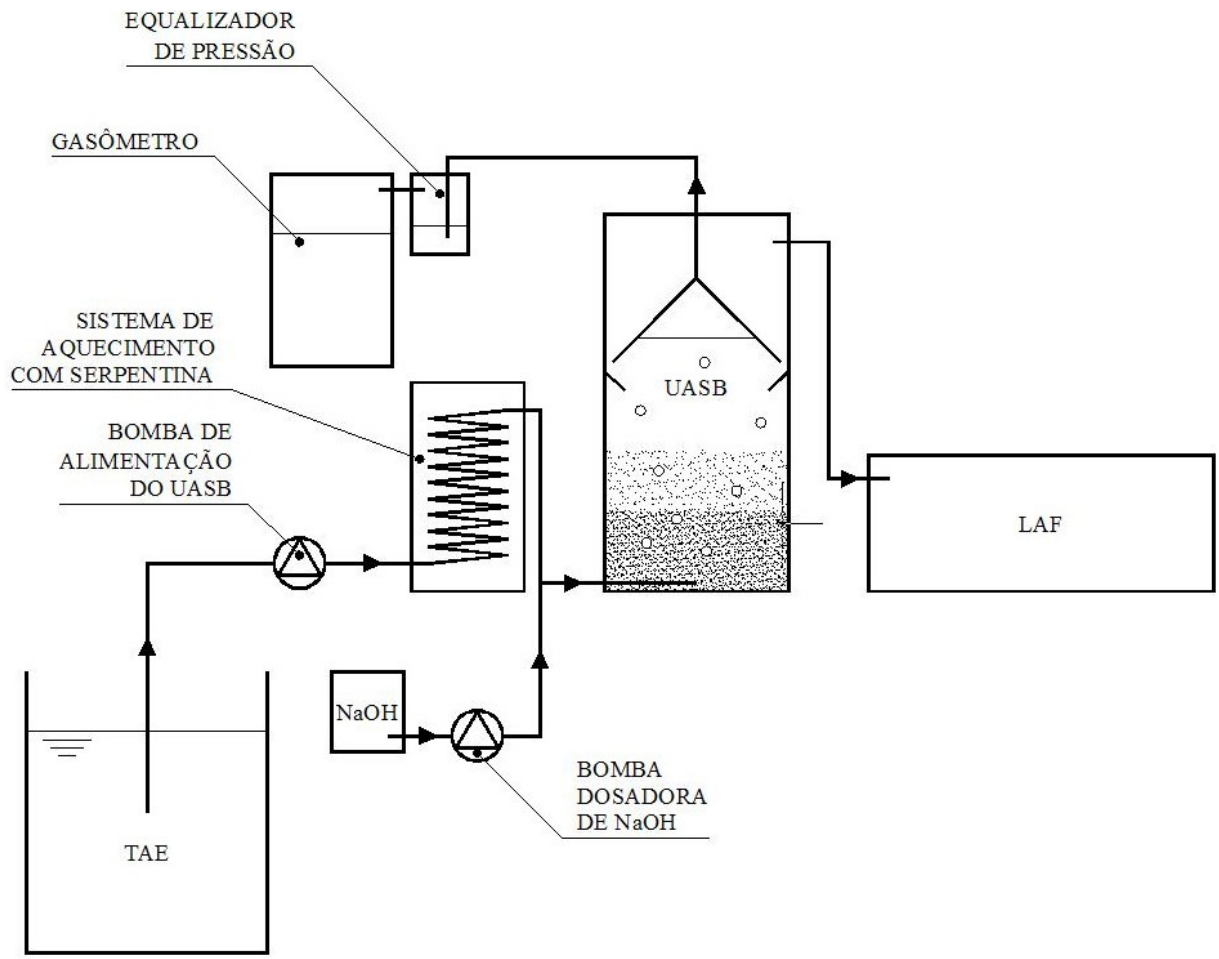

Figura 1 - Sistema utilizado, em escala laboratorial, para o tratamento das ARC e produção de metano.

\section{Análises laboratoriais}

As análises de demanda química de oxigênio (DQO), demanda bioquímica de oxigênio $\left(\mathrm{DBO}_{5}\right), \mathrm{pH}$, temperatura, Nitrogênio (N), Fósforo (P), compostos fenólicos, alcalinidade total (AT), sólidos totais (ST), sólidos totais fixos (STF) e sólidos totais voláteis (STV) foram realizadas segundo o Standard Methods for Examination of Water and Wastewater (AMERICAN PUBLIC HEALTH ASSOCIATION-APHA, 1998). As análises de alcalinidade parcial (AP), para se determinar, separadamente, as parcelas de alcalinidade, em razão dos bicarbonatos e dos ácidos voláteis totais, e alcalinidade intermediária (AI) foram realizadas segundo metodologia proposta por Ripley et al. (1983).

\section{Monitoramento do sistema}

O processo de tratamento foi dividido em períodos e subperíodos (Tabela 1) em função da variação do $\mathrm{pH}$ e da alcalinidade, pela adição ou não de Hidróxido de sódio $(\mathrm{NaOH})$ na ARC, que ocorreu no TAE ou no reator UASB.

\section{Métodos analíticos}

Foi utilizada cromatografia gasosa para determinar a composição química do biogás e a determinação da concentração de metano, que possui grande poder de resolução e boa velocidade de separação, além de permitir o monitoramento contínuo do efluente na coluna, a medição quantitativa exata, análises com reprodutibilidade e repetibilidade e automação do processo analítico e do tratamento de dados. Foi utilizado cromatógrafo gasoso (Tabela 2), da marca Varian Chrompack CP-3800, calibrado, utilizando-se padrão de metano da White Martins Gases Industriais Ltda (2006), acoplado a um computador. O nitrogênio foi utilizado como gás de arraste e gás make-up. A coluna utilizada foi a de Restek Rt-Q-PLOT, de 0,53 mm de diâmetro interno (d.i.) e $15 \mathrm{~m}$ de comprimento. O detector utilizado foi o de ionização de chama - DIC, alimentado por hidrogênio e ar sintético.

\section{Estimativa da produção de biogás}

O método utilizado nos cálculos, da estimativa da produção de biogás e de metano, foi da DQO removida, com correção da temperatura e da pressão. Para a conversão do volume de metano produzido em volume de biogás, foi considerado o valor mínimo de referência (70\%) da concentração de metano no biogás produzido no tratamento do esgoto doméstico. 
A atividade metanogênica, que é a capacidade dos microrganismos anaeróbios em converter substratos orgânicos em metano, foi calculada em termos de atividade metanogênica no reator, baseada na estimativa da produção de metano pela DQO removida por quilograma de biomassa (representada pelos STV) presente no reator UASB por dia. Para o cálculo de conversão do metano produzido em biogás, foi considerado, como referência, o biogás com uma concentração de 70 a $80 \%$ de metano (Cassini, 2003; Metcalf \& Eddy, 2003; Chernicharo, 2007).

Para os cálculos estatísticos, utilizou-se o software Excel da Microsoft e o Software Sisvar, versão 4.6 (Ferreira, 2003).

\section{RESULTADOS E DISCUSSÃO}

Os valores máximo, médio e mínimo do volume da produção de biogás por quilograma de matéria orgânica removida, em termos de DQO, e a concentração de metano presente, considerando-se o tratamento total, são apresentados na Tabela 3. Na Tabela 4, apresentase a comparação das concentrações médias de metano no biogás, considerando-se os períodos e os subperíodos, pelo teste de Student-Newman-Keuls (SNK). Enquanto, na Figura 2, apresenta a variação da concentração média de metano nos períodos e subperíodos, na Figura 3, apresenta-se a variação da sua

Tabela 1 - Divisão dos períodos e sub-períodos utilizados durante o monitoramento do sistema, em escala laboratorial, utilizado no tratamento das ARC.

\begin{tabular}{cccccc}
\hline Período & Sub-período & Data & Total de dias & NaOH(\%) & Local de adição \\
\hline IV & A & $22 / 03 / 06-11 / 04 / 06$ & 21 & 10,0 & TAE \\
IV & B & $12 / 04 / 06-08 / 05 / 06$ & 27 & ----- & ---- \\
V & A & $09 / 05 / 06-22 / 05 / 06$ & 14 & ---- & ---- \\
V & B & $23 / 05 / 06-09 / 06 / 06$ & 18 & 10,0 & TAE \\
VI & A & $10 / 06 / 06-15 / 06 / 06$ & 06 & 10,0 & TAE \\
VI & B & $16 / 06 / 06-30 / 06 / 06$ & 15 & 2,5 & UASB* \\
\hline
\end{tabular}

*Adição de $\mathrm{NaOH}$ com bomba dosadora.

Tabela 2 - Parâmetros do cromatógrafo gasoso Varian chrompack CP-3800, utilizado para determinação da concentração de metano no biogás, obtido a partir da ARC.

\begin{tabular}{ll}
\hline Parâmetros do cromatógrafo & Valor \\
\hline Temperatura da coluna $\left({ }^{\circ} \mathrm{C}\right)$ & 50 \\
Temperatura do injetor $(\mathrm{oC})$ & 220 \\
Temperatura do detector (oC) & 250 \\
Velocidade linear dos gases (cm.s-1) & 51 \\
Vazão de N2 na coluna (mL.min-1) & 6,2 \\
Vazão total na coluna (mL.min-1) & 72,4 \\
Pressão de N2 total $(\mathrm{kPa})$ & 585,5 \\
Pressão de H2 (kPa) & 413,3 \\
Pressão de Ar sintético (kPa) & 585,5 \\
Pressão na coluna $(\mathrm{kPa})$ & 8,1 \\
\hline
\end{tabular}

Tabela 3 - Produção máxima, média e mínima do volume de biogás e concentração de metano, observados durante o funcionamento do sistema, considerando-se o período completo do tratamento das ARC.

\begin{tabular}{ccc}
\hline Valores & Biogás $\left(\mathrm{m}^{3} \mathrm{~kg}^{-1} \mathrm{DQO}\right)$ & $\mathrm{CH}_{4}(\%)$ \\
\hline Máximo & 0,602 & 68,14 \\
Média & 0,580 & 57,19 \\
Mínimo & 0,545 & 48,60 \\
\hline
\end{tabular}


Tabela 4 - Valores médios das concentrações de metano, durante o funcionamento do sistema, considerando-se os períodos e os sub-períodos do tratamento das ARC.

\begin{tabular}{cc}
\hline Período e sub-período & Metano (\%) \\
\hline IV-A & $63,98 \mathrm{a}$ \\
IV-B & $57,22 \mathrm{~b}$ \\
V-A & $55,14 \mathrm{~b}$ \\
V-B & $62,03 \mathrm{a}$ \\
VI-A & $55,39 \mathrm{~b}$ \\
VI-B & $55,33 \mathrm{~b}$ \\
\hline
\end{tabular}

Médias seguidas da mesma letra não diferem entre si pelo teste SNK, a 5\% de probabilidade.

concentração, considerando-se o tratamento total. Speece (1996), considera que, no processo de digestão de esgotos domésticos, as proporções típicas de metano e de dióxido de carbono, no biogás, são de 70 a $80 \%$ para o metano e de 30 a $20 \%$ para o gás carbônico, respectivamente.

Percebe-se que houve diferenças significativas, a $5 \%$ de probabilidade, na concentração de metano entre os períodos. As médias de concentração de metano foi variável nos subperíodos, assim como, os valores observados durante o período completo do experimento, sendo o valor máximo de 63,98 para o período e subperíodo IV-A e mínimo de 55,14 para o V-A. Nesses períodos, houve adição de $\mathrm{NaOH}$ na $\mathrm{ARC}$ e, pode ser verificado que, o $\mathrm{pH}$ no A-UASB manteve-se com valores mais próximos da neutralidade e a relação AI/AP foi a menor obtida, tanto no A-UASB quanto no E-UASB; a acidez apresentou os menores valores.

Os valores médios obtidos, das eficiências de remoção de poluentes e das análises laboratoriais, durante o tratamento da ARC, no ano de 2006, podem explicitar as variações das concentrações médias de metano ocorridas nos períodos e nos subperíodos.

As eficiências de remoção da $\mathrm{DQO}$ e $\mathrm{DBO}_{5}$ atingiram valores acima dos $70 \%$, demonstrando ser o reator UASB uma boa opção no tratamento das ARC. Na remoção do nitrogênio, do fósforo e dos compostos fenólicos ocorreram variações, possivelmente provocadas por choques de cargas e pelo aumento gradativo da concentração dos mesmos no reator UASB. Pelos resultados variáveis da eficiência de remoção dos compostos fenólicos, verificou-se a dificuldade da degradação desses compostos no reator UASB, podendo estes interferirem no metabolismo das Archaeas metanogênicas (Tabela 5).

Kivaisi \& Rubindamayugi (1996), ao realizarem um trabalho, utilizando tratamento anaeróbio em batelada das
ARC, em escala laboratorial, obtiveram produção de metano de $0,30 \mathrm{~m}^{3} \mathrm{~kg}^{-1}$ DQO removida.

Dinsdale et al. (1997), tratando ARC da indústria de café solúvel, utilizando reator UASB de bancada, obtiveram a produção média de biogás e de metano, em relação à DQO removida, de $0,46 \mathrm{~m}^{3} \mathrm{~kg}^{-1} \mathrm{DQO}$ e de $0,29 \mathrm{~m}^{3} \mathrm{~kg}^{-1} \mathrm{DQO}$, respectivamente. A porcentagem média de metano no biogás foi de $62,3 \%$.

Silva \& Campos (2005), tratando águas residuárias de beneficiamento de café por via úmida, com DQO total em torno de $3.250 \mathrm{mg} \mathrm{L}^{-1}$, em reator UASB, em escala de bancada $(11,7 \mathrm{~L})$, com TDH de $69 \mathrm{~h}$ e COV de 0,59 g DQO $\mathrm{L}^{-1} \mathrm{~d}^{-1}$, obtiveram eficiência de remoção de DQO total de $78 \%$.

Na Tabela 6, apresentam-se os valores médios obtidos para o pH e a temperatura. De acordo com Chernicharo (2007), as Archaeas metanogênicas têm crescimento ótimo na faixa de $\mathrm{pH}$ entre 6,6 e 7,4, embora possa ocorrer estabilidade na formação de metano em faixa mais ampla, entre 6,0 e 8,0. Pode-se verificar que, nos períodos em que foi adicionado $\mathrm{NaOH}$ à $\mathrm{ARC}, \mathrm{o} \mathrm{pH}$ manteve-se próximo de 7,0. Os baixos valores do $\mathrm{pH}$, de 5,35 e 4,79, ocorrerem nos períodos e subperíodos IV-B e $\mathrm{V}$-A, sem adição de $\mathrm{NaOH}$.

As variações de temperatura, com amplitude de $8,9^{\circ} \mathrm{C}$ no período completo, embora tenha se mantido dentro da faixa mesofílica, ficou abaixo da temperatura ideal de produção de metano, que é em torno de $40^{\circ} \mathrm{C}$. Percebe-se que, a cada aumento da temperatura, houve aumento da concentração de metano.

Souza et al. (2008) montaram um sistema de digestão anaeróbia, em escala laboratorial, para estudarem o efeito do tempo de detenção hidráulica e da temperatura sobre a produção de metano a partir de dejetos de suínos e encontraram diferença significativa na produção de biogás e na produção volumétrica de metano (PM), em razão da diminuição do TDH e ao 
aumento da temperatura. Os maiores valores de PM (1,40 $\mathrm{L}$ de $\mathrm{CH} 4$ por L de volume útildo biodigestor por dia) foram observados no TDH de 10 dias e na temperatura de $40{ }^{\circ} \mathrm{C}$, nos biodigestores.

Foi verificado também que, as maiores concentrações de metano no biogás, foram obtidas nos períodos em que o pH estava mais próximo da neutralidade $(7,00)$ e a acidez mais baixa. Isso mostra que a adição do $\mathrm{NaOH}$ foi importante para o aumento da alcalinidade e diminuição da acidez do líquido afluente que, geralmente, é abaixo de 4,0 (Tabela 7).

De acordo com Metcalf \& Eddy (2003) e Speece (1996), para o tratamento de efluentes domésticos, valores de alcalinidade total entre 2.000 a 4.000 são os ideais para manter o reator tamponado. Como o maior valor encontrado foi de 1.597,67 $\mathrm{mg} \mathrm{L}^{-1}$, para o período-subperíodo VI-B, pode-se dizer que, ou o reator não manteve o tamponamento ou que os valores de referência para esgoto doméstico são elevados para o efluente da ARC.

Bruno \& Oliveira (2008) efetuaram tratamento anaeróbio das ARC em reatores UASB, utilizando dois reatores UASB (R1 e R2), em escala laboratorial, e três ensaios. No ensaio 1, ocorreu diminuição do $\mathrm{pH}$ dos efluentes do R1 e do R2 após 15 dias de operação, atingindo os menores valores do experimento, $\mathrm{pH}$ de $4,7 \mathrm{e}$ 4,9 , respectivamente, comprometendo o desempenho do sistema de tratamento. A queda do $\mathrm{pH}$ nos efluentes do R1 e do R2, no ensaio 1, foi relacionada com o aumento da concentração de ácidos voláteis totais, provocada pelos acréscimos de carga orgânica e de tóxicos (fenóis) no afluente, que ocorreram após os 15 dias de operação. O mesmo não ocorreu nos ensaios 2 e 3 , quando os valores de $\mathrm{pH}$ não foram limitantes para a metanogênese nos reatores a sua estabilidade foi atribuída aos altos valores

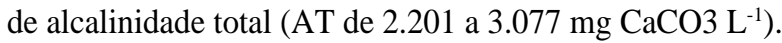

A relação entre os sólidos presentes no reator que representam nele a biomassa e a concentração de metano, foi inversa, ou seja, com o aumento da biomassa no reator houve diminuição da concentração de metano, indicando que a presença da biomassa ativa não contiubiu para o aumento da concentração de metano, porém, como esses dois fatores são correlacionados, admite-se que pode ter havido interferências no reator, reduzindo a atividade metanogênica das árquéias metanogênicas (AM), como pode ser visto na Tabela 8 .

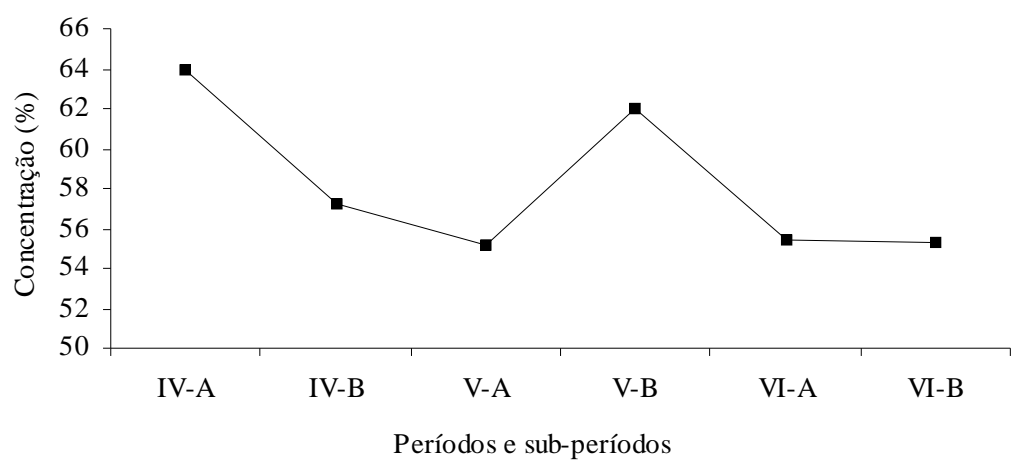

Figura 2 - Concentração média de metano considerando-se os períodos e os sub-períodos do tratamento das ARC.

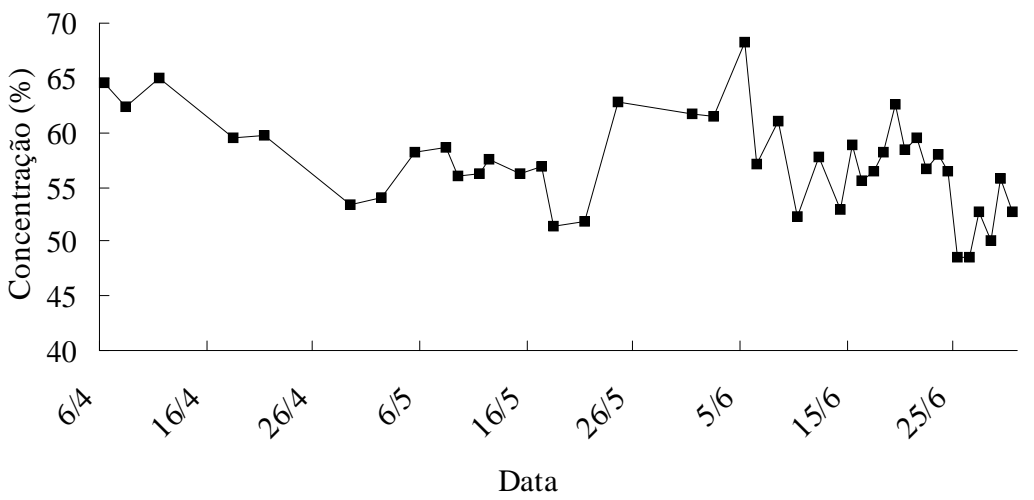

Figura 3 - Concentração de metano durante o funcionamento do sistema, considerando-se o período completo do tratamento das ARC. 
Tabela 5 - Concentração de metano (\%) e eficiência (\%) de remoção dos poluentes, observados no reator UASB, durante o funcionamento do sistema, considerando-se o período completo do tratamento das ARC.

\begin{tabular}{ccccccc}
\hline $\begin{array}{c}\text { Período e } \\
\text { subperíodo }\end{array}$ & $\begin{array}{c}\mathrm{CH}_{4} \\
(\%)\end{array}$ & $\begin{array}{c}\mathrm{DQO} \\
(\%)\end{array}$ & $\begin{array}{c}\mathrm{DBO}_{5} \\
(\%)\end{array}$ & $\begin{array}{c}\mathrm{N} \\
(\%)\end{array}$ & $\begin{array}{c}\text { Compostos } \\
(\%)\end{array}$ & $\begin{array}{c}\text { Ponólicos } \\
(\%)\end{array}$ \\
\hline IV-A & 63,98 & 76,09 & 75,50 & $-23,35$ & 15,76 & 19,54 \\
IV-B & 57,22 & 82,17 & 86,63 & 32,51 & $-7,43$ & 22,04 \\
V-A & 55,14 & 72,04 & 73,99 & $-0,79$ & 37,16 & $-3,75$ \\
V-B & 62,03 & 77,21 & 78,17 & 1,89 & 20,66 & 1,78 \\
VI-A & 55,39 & 70,54 & 71,95 & --- & 27,38 & -- \\
VI-B & 55,33 & 74,43 & 73,25 & 13,37 & 30,43 & 27,75 \\
\hline
\end{tabular}

Tabela 6 - Concentração de metano, pH e temperatura observados no afluente do UASB (A-UASB) e no efluente do UASB (E-UASB), durante o funcionamento do sistema, considerando-se o período completo do tratamento das ARC.

\begin{tabular}{cccccc}
\hline $\begin{array}{c}\text { Período e } \\
\text { subperíodo }\end{array}$ & $\begin{array}{c}\mathrm{CH}_{4} \\
(\%)\end{array}$ & $\begin{array}{c}\mathrm{pH} \\
\text { A-UASB }\end{array}$ & $\begin{array}{c}\text { Temp }\left({ }^{\circ} \mathrm{C}\right) \\
\text { A-UASB }\end{array}$ & $\begin{array}{c}\mathrm{pH} \\
\text { E-UASB }\end{array}$ & $\begin{array}{c}\text { Temp }\left({ }^{\circ} \mathrm{C}\right) \\
\text { E-UASB }\end{array}$ \\
\hline IV-A & 63,98 & 6,93 & 26,47 & 7,34 & 26,59 \\
IV-B & 57,22 & 5,35 & 25,01 & 6,73 & 24,78 \\
V-A & 55,14 & 4,79 & 23,34 & 6,29 & 22,10 \\
V-B & 62,03 & 6,34 & 23,22 & 6,97 & 21,46 \\
VI-A & 55,39 & 6,50 & 22,50 & 7,34 & 20,90 \\
VI-B & 55,33 & 6,56 & 22,82 & 7,19 & 20,31 \\
\hline
\end{tabular}

Tabela 7 - Concentração de metano (\%), alcalinidade Ripley $\left(\mathrm{mg} \mathrm{CaCO}_{3} \mathrm{~L}^{-1}\right)$ e acidez $\left(\mathrm{mg} \mathrm{CaCO}_{3} \mathrm{~L}^{-1}\right)$ observados no afluente e no efluente do UASB (A-UASB e B-UASB), durante o funcionamento do sistema, considerando-se os períodos e os sub-períodos do tratamento das ARC. AP: alcalinidade parcial; AI: alcalinidade intermediária; AT: alcalinidade total

\begin{tabular}{|c|c|c|c|c|c|c|}
\hline \multicolumn{7}{|c|}{ A-UASB } \\
\hline $\begin{array}{c}\text { Período e } \\
\text { sub-período }\end{array}$ & $\begin{array}{l}\mathrm{CH}_{4} \\
(\%)\end{array}$ & $\begin{array}{c}\mathrm{AP} \\
\left(\mathrm{mg} \mathrm{CaCO}_{3} \mathrm{~L}^{-1}\right)\end{array}$ & $\begin{array}{c}\mathrm{AI} \\
\left(\mathrm{mg} \mathrm{CaCO}_{3} \mathrm{~L}^{-1}\right)\end{array}$ & $\begin{array}{c}\mathrm{AT} \\
\left(\mathrm{mg} \mathrm{CaCO}_{3} \mathrm{~L}^{-1}\right)\end{array}$ & AI/AP & $\begin{array}{c}\text { Acidez } \\
\left(\mathrm{mg} \mathrm{CaCO}_{3} \mathrm{~L}^{-1}\right)\end{array}$ \\
\hline IV-A & 63,98 & 431,30 & 485,87 & 917,17 & 1,3 & 118,01 \\
\hline IV-B & 57,22 & 0,00 & 492,16 & 492,16 & - & 209,14 \\
\hline V-A & 55,14 & 36,47 & 308,88 & 345,35 & 3,8 & 248,71 \\
\hline V-B & 62,03 & 175,31 & 576,86 & 752,17 & 3,6 & 101,75 \\
\hline VI-A & 55,39 & 340,07 & 917,35 & $1.257,42$ & 2,7 & 168,39 \\
\hline VI-B & 55,33 & 356,03 & $1.005,11$ & $1.361,15$ & 3,8 & 154,55 \\
\hline \multicolumn{7}{|c|}{ B-UASB } \\
\hline $\begin{array}{c}\text { Período e } \\
\text { subperíodo }\end{array}$ & $\mathrm{CH}_{4}$ & $\begin{array}{c}\mathrm{AP} \\
\left(\mathrm{mg} \mathrm{CaCO}_{3} \mathrm{~L}^{-1}\right)\end{array}$ & $\begin{array}{c}\mathrm{AI} \\
\left(\mathrm{mg} \mathrm{CaCO}_{3} \mathrm{~L}^{-1}\right)\end{array}$ & $\begin{array}{c}\mathrm{AT} \\
\left(\mathrm{mg} \mathrm{CaCO}_{3} \mathrm{~L}^{-1}\right)\end{array}$ & $\mathrm{AI} / \mathrm{AP}$ & $\begin{array}{c}\text { Acidez } \\
\left(\mathrm{mg} \mathrm{CaCO}_{3} \mathrm{~L}^{-1}\right)\end{array}$ \\
\hline IV-A & 63,98 & 752,16 & 321,04 & $1.073,20$ & 0,4 & 76,36 \\
\hline IV-B & 57,22 & 604,88 & 286,98 & 891,86 & 0,5 & 92,13 \\
\hline V-A & 55,14 & 317,88 & 256,16 & 574,04 & 1,2 & 113,84 \\
\hline V-B & 62,03 & 460,89 & 315,44 & 776,34 & 0,7 & 50,18 \\
\hline VI-A & 55,39 & $1.048,76$ & 366,39 & $1.415,15$ & 0,4 & 49,39 \\
\hline VI-B & 55,33 & 922,67 & 675,00 & $1.597,67$ & 0,8 & 100,01 \\
\hline
\end{tabular}


Os valores da concentração de metano e da atividade metanogênica (AM) no reator UASB podem ser vistos na Tabela 9.

Como o aumento da atividade metanogênica não implicou em aumento da concentração de metano, o que pode ter acontecido em razão do aumento de outros componentes do biogás, como o $\mathrm{CO}_{2}$, o $\mathrm{H}_{2} \mathrm{~S}$ ou outros gases.

Problemas operacionais ocorridos no reator UASB, tais como o entupimento do sistema, choques de cargas e varreduras (wash-outs), ocorridos durante o aumento das concentrações das vazões, também proporcionaram diminuições na produção do biogás.

A partir do período $\mathrm{V}$, ocorreu aumento da carga e, como nesses casos, há uma tendência de acúmulo de matéria orgânica nas paredes internas das tubulações, provocando a diminuição do volume útil e entupimentos das mesmas, o que provocou variações nas vazões. No período VI-B, quando foi utilizada bomba dosadora para enviar $\mathrm{NaOH}$ para a entrada do UASB, os entupimentos, tanto na bomba de ARC quanto na de $\mathrm{NaOH}$, foram mais frequentes.

Os menores valores da concentração de metano foram obtidos no período VI (principalmente nos dias 25, 26 e 28/06/06) e podem estar relacionados com a ocorrência de baixos valores de $\mathrm{pH}$, altos valores AI/AP e variações frequentes da vazão, decorrentes de entupimentos. Nesse período, a concentração de compostos fenólicos na ARC foi maior do que nos outros e pode ter interferido no metabolismo das Archaeas metanogênicas.

Tabela 8 - Concentração de metano (\%) e presença de sólidos no reator UASB durante o funcionamento do sistema, considerando-se os períodos e os subperíodos do tratamento das ARC.

\begin{tabular}{ccccc}
\hline Período e sub-período & $\mathrm{CH}_{4}(\%)$ & $\mathrm{ST}\left(\mathrm{mg} \mathrm{L}^{-1}\right)$ & $\mathrm{STF}\left(\mathrm{mg} \mathrm{L}^{-1}\right)$ & $\mathrm{STV}\left(\mathrm{mg} \mathrm{L}^{-1}\right)$ \\
\hline IV-A & 63,98 & 26.729 & 10.646 & 16.083 \\
IV-B & 57,22 & 32.467 & 10.600 & 21.777 \\
V-A & 55,14 & 48.927 & 14.952 & 33.975 \\
V-B & 62,03 & 44.228 & 12.971 & 31.257 \\
VI-A & 55,39 & $*$ & $*$ & $*$ \\
VI-B & 55,33 & 50.021 & 12.863 & 37.157 \\
\hline
\end{tabular}

* Não houve análise neste sub-período.

Tabela 9 - Concentração de metano (\%) e atividade metanogênica (AM) no reator UASB, durante o funcionamento do sistema, considerando-se os períodos e os sub-períodos do tratamento das ARC.

\begin{tabular}{ccc}
\hline Período e sub-período & $\mathrm{CH}_{4}(\%)$ & $\mathrm{AM}\left(\mathrm{m}^{3} \mathrm{CH}_{4} \mathrm{kgSVT}^{-1} \mathrm{~d}^{-1}\right)$ \\
\hline IV-A & 63,98 & 0,051 \\
IV-B & 57,22 & 0,073 \\
V-A & 55,14 & 0,061 \\
V-B & 62,03 & 0,049 \\
VI-A & 55,39 & $*$ \\
VI-B & 55,33 & 0,167 \\
\hline
\end{tabular}

* Não houve análise neste sub-período. 


\section{CONCLUSÕES}

As variáveis que mais influenciaram a variação das concentrações de metano no biogás produzido a partir do sistema de tratamento das ARC, foram a temperatura, o $\mathrm{pH}$, a acidez e a concentração dos compostos fenólicos presentes.

As maiores concentrações de metano no biogás foram verificadas nos períodos em que o $\mathrm{pH}$ estava mais próximo da neutralidade $(7,00)$. A adição de $\mathrm{NaOH}$ foi importante no aumento da alcalinidade parcial, que melhorou o tamponamento do reator. Os compostos fenólicos presentes fizeram com que a concentração de metano diminuísse, porque esses compostos são tóxicos ao metabolismo das Archaeas metanogênicas.

As eficiências de remoção de $\mathrm{DQO}, \mathrm{DBO}_{5}, \mathrm{~N}$ e P, em todos os períodos, não demonstraram correlações consideráveis na variação da concentração de metano no biogás das ARC.

Há necessidade de funcionamento do reator com um controle sistemático dos parâmetros que estão diretamente ligados à biomassa deste, como a temperatura, o pH, a acidez e a alcalinidade e dos parâmetros físicos de funcionamento do reator, como a vazão e as cargas aplicadas, evitando-se choques de cargas e varreduras, para que se obtenha melhores valores de concentração de metano.

\section{AGRADECIMENTOS}

Os autores agradecem à FAPEMIG, $\mathrm{CNPq}$ e ao LAADEG/UFLA.

\section{REFERÊNCIAS BIBLIOGRÁFICAS}

AMERICAN PUBLIC HEALTH ASSOCIATION. Standard methods for the examination of water and wastewater. Washington, 1998.

BARRETO, A. C.; CAMPOS, C. M. M. Avaliação de um sistema de irrigação autopropelido aplicando água residuária de suinocultura. Ciência e Agrotecnologia, Lavras, v. 33, Edição Especial, p. 1752-1757, 2009.

BRUNO, M.; OLIVEIRA, R.A. de. Tratamento anaeróbio de águas residuárias do beneficiamento de café por via úmida em reatores UASB. Engenharia Agrícola,

Jaboticabal, v.28, n.2, p.364-377, abr./jun. 2008.

CAMPOS, C.M.M. Physical aspects affecting granulations in UASB Reactors. 1990. 459f. Thesis (Ph.D.)University of Newcastle upon Tyne, Newcastle, 1990.
CAMPOS, C.M.M.; CARMO, A.C. do; LUIZ, F.A.R. de. Impacto ambiental causado pela poluição hídrica proveniente do processamento úmido do café. Revista Cafeicultura, Patrocínio, v.1, n.4, nov. 2002.

CASSINI, S.T. (Coord.). Digestão de resíduos sólidos orgânicos e aproveitamento do Biogás. Rio de Janeiro: ABES/Rima, 2003. 210p. (Projeto PROSAB).

\section{CHERNICHARO, C.A.L. Princípios do tratamento} biológico de águas residuárias: reatores anaeróbios. Belo Horizonte: UFMG, 2007. v.5, 379p.

DINSDALE, R.M.; HAWKES, F.R.; HAWKES, D.L. Comparison of mesophilic and thermophilic upflow anaerobic sludge blanket reactors treating instant coffee production wastewater. Revista Water Resources, v.31, n.1, p.163-169, 1997.

FERREIRA, D.F. Software Sisvar: versão 4.6, build 63. Lavras: DEX/UFLA, 2003. Disponível em: <www.ufla.bry. Acesso em: 10 jun. 2006.

KIVAISI, A.K.; RUBINDAMAYUGI, M.S.T. The potencial of agroindustrial residues for production of biogas and eletricity in Tanzânia. Dar es salaam: University of Dar es salaam, 1996. Revista Renewable Energy, v.9, p.917-921, 1996. Disponível em: <http:// LwWw.sciencedirect.com/science/journals mar. 2005.

LORA, E.S.; ANDRADE, R.V. Biomass as energy source in Brazil. Renewable and Sustainable Energy Reviews, v.13, p.777-788, 2009. Disponível em: $<$ http/LwW.sciencedirect.com>- Acesso em: 19 mar. 2009.

LUSTE, S.; LUOSTARINEN, S.; SILLANPAA, M. Effect of pre-treatments on hydrolysis and methane production potentials of by-products from meat-processing industry. Journal of Hazardous Materials, v.164, p.247255, 2009. Disponível em: 〈http//ww.sciencedirect.com>. Acesso em: 19 mar. 2009.

METCALF; EDDY. Wastewater engineering: treatment, disposal and reuse. 4.ed. rev. New York: McGraw-Hill, 2003. 1819p. 
PRADO, M.A.C. Produção de biogás no tratamento dos efluentes líquidos de Coffea arabica $\mathrm{L}$. em reator UASB para o potencial aproveitamento na secagem do café. 2006. 206p. Dissertação (Mestrado em

Engenharia Agrícola)-Universidade Federal de Lavras, Lavras, 2006.

RIPLEY, L.E.; BOYLE, W.C.; CONVERSE, J.C. Improved alkalimetric monitogirng for anaerobic digestion of highstrenght wastes. Journal WPCF, v.58, n.5, p.406-411, 1983.

SILVA, B.A.; CAMPOS, C.M.M. Tratamento anaeróbio de efluentes líquidos gerados no beneficiamento úmido do café. In: CONGRESSO BRASILEIRO DE

ENGENHARIA AGRÍCOLA, 34., 2005, Canoas. Anais... Jaboticabal: Associação Brasileira de Engenharia Agrícola, 2005. CD-ROM.
SOUZA, C.F.; CAMPOS, J.A.; SANTOS, C.R. dos; BRESSAN, W.S.; MOGAMI, C.A. Produção volumétrica de metano: dejetos de suínos. Ciência e Agrotecnologia, Lavras, v.32, n.1, p.219-224, jan./fev. 2008.

SPEECE, R.E. Anaerobic biotechnology: for industrial wastewater. Nashville: Archae, 1996. 394p.

SPERLING, M. von. Introdução à qualidade das águas e ao tratamento de esgotos. Belo Horizonte: UFMG, 1996b. v.1, 246p.

SPERLING, M. von. Princípios básicos do tratamento de esgotos. Belo Horizonte: UFMG, 1996a. v.2, 246p.

WHITE MARTINS GASES INDUSTRIAIS LTDA.

Certificado de garantia de qualidade: certificado número 40036800. São Paulo, 2006. 